\title{
Los estudios e investigaciones en comunicación en nuestros tiempos neoliberales y posmodernos
}

Enrique Guinsberg ${ }^{1}$

NA NOTORIA CRISIS Y CONFUSIÓN se observa entre los estudiosos de la comunicación, que claramente se expresan en las múltiples preguntas que pueden hacerse al respecto, entre las que destacan las siguientes: ¿a qué responden las características dominantes de los estudios e investigaciones que se realizan?, ¿por qué la notoria y creciente disconformidad - más hablada que escrita - que se observa en importantes sectores al menos latinoamericanos?, ¿se perdió la perspectiva crítica de épocas anteriores por adhesión a las "modas" teóricas actuales tanto comunicativas como sociales y políticas?, ¿se puede también en este campo específico señalar la preponderancia de temáticas y formas de estudio "domesticadas" y "bizantinas"??

Evidentemente esta discusión no es específica del campo de la comunicación sino que lo que aquí se produce es expresión de un fenómeno generalizado que adquiere gran fuerza en todas las disciplinas sociales de nuestro tiempo: "crisis" de todo (de paradigmas, ${ }^{3}$ de relativas seguridades anteriores, de utopías), consecuente

1. Profesor-investigador, Departamento de Educación y Comunicación. Universidad Autónoma Metropolitana, Xochimilco.

2. Términos que han sido utilizados para el campo psicológico y psicoanalítico indicando la ausencia de perspectiva crítica respecto a la producción de psico(pato)logía por parte de los marcos culturales hegemónicos, y por el no estudio de las problemáticas centrales de nuestra época concreta al prioriozarse los detalles o aspectos muchas veces también importantes pero menores o no centrales (Guinsberg, $1991 \mathrm{a}, 1997 \mathrm{a}, 2000 \mathrm{a})$.

3. Con base en las conocidas postulaciones de Kuhn, Hodge y Tripp señalan que "de los periodos de 'ciencia normal' pasamos a fases de crisis, en gran parte como resultado de la acumulación de las anormalidades y los resultados contradictorios que no pueden ser explicados en el marco del actual paradigma" (Hodge y Tripp, 1986:230). El periodo actual se caracteriza no sólo por la incorporación de múltiples nuevos conocimientos, sino por un replanteo general de prácticamente todos los marcos teóricos, en particular los de las llamadas "ciencias sociales". 
y necesaria crítica de las perspectivas teóricas y prácticas precedentes, correlativa apertura $a$ y búsqueda de nuevos caminos, a lo que se agrega en el terreno comunicativo el surgimiento de nuevas problemáticas producto del altísimo desarrollo de la tecnología y la aparición de nuevos sistemas de comunicación cualitativamente diferentes a los precedentes.

Pero todo esto debe ubicarse en el contexto que le da un sentido específico. Así como la perspectiva crítica latinoamericana de fines de los sesenta y de los setenta fue expresión del Zeitgest de tal período —contestatario, rebelde y/o revolucionario, etcétera-, las actuales deben ubicarse como producciones de una época muy diferente signada por el modelo de economía de mercado neoliberal y la globalización, la ausencia de propuestas de cambios sociales radicales, el auge teórico de las variantes "posmodernas", etcétera. Contexto que ha hecho cambiar marcadamente el sentido de la política y de lo político y el rol de los intelectuales que, en forma preponderante aunque no absoluta, han perdido o reducido su perspectiva crítica para tomar caminos hoy llamados "pragmáticos", no pocas veces sin conciencia de esto y de cómo favorecen al modelo hegemónico (Guinsberg, 1999).

Esto no se ha dado de golpe sino a través de distintos pasos: al respecto debe recordarse cómo los cambios políticos latinoamericanos que se inician en los setenta - golpes militares contrainsurgentes, pérdida de fuerza de los sectores populares y su posterior derrota - produjeron cambios significativos en las perspectivas teóricas de las disciplinas sociales: auge de posturas "lacanistas" en el campo psi, desarrollo de las teorías del discurso y de la semiótica entre otras en el de la comunicación, etcétera. Pero en todos los casos se produce algo fundamental que se desarrollará como eje de este ensayo: un marcado proceso de despolitización en la elección de las problemáticas de estudio y de investigación, en las formas de encararlas, en los vínculos de los comunicólogos con las instituciones e incluso en las perspectivas de estas.

Aquí se debe hacer una aclaración que puede también ser una defensa ante lectores ubicados en posturas de moda y/o (pos)modernas, que muy probablemente sonreirán o lo expresarán irónicamente con la suficiencia de quienes creen que lo único valioso es estar en lo actual o están seducidos ante la espectacularidad y promesas idílicas de las nuevas tecnologías: no se trata de una ubicación en posturas "dinosáuricas" y nostálgicas inversas, es decir acríticas de lo realizado previamente y de sus carencias, o negadoras de lo múltiple nuevo que existe en el campo comunicativo y su incidencia cada vez mayor en toda la vida social. Todo lo contrario: se trata de hacer una evaluación realmente crítica, lo que significa tanto abandonar lo erróneo como recuperar lo válido, sin caer en la vieja falacia de "tirar al niño junto 
con el agua sucia de la bañera". Se trata también de producir una reconfiguración de premisas que no han perdido su sentido sino todo lo contrario, o sea que se han potenciado y así debe comprenderse, entre ellas las viejas y clásicas preguntas que marcaron toda una época sin perder hoy su pertinencia: ¿qué contenidos se difunden a través de unos medios de comunicación masivos con cada vez mayor penetración?, ¿cuáles son los intereses a los que responden y quiénes los controlan?, ¿la proliferación de medios permite mayores opciones de acceso a contenidos realmente plurales y por tanto a amplitud de elección y a una mayor libertad ideológica y política? Se trata entonces de algo central: la necesidad de ver todo lo nuevo con base en la ubicación en su contexto, sin perder nunca de vista cómo lo comunicativo es parte integrante de una totalidad que lo determina, y entendiendo que esta totalidad hoy responde a las señaladas características de un neoliberalismo y una globalización que, como todo modelo, no es neutro sino responde a valores precisos y concretos. $\mathrm{Y}$ se trata también de la capacidad de un pensamiento crítico tanto hacia ese modelo como hacia los marcos teóricos actuales del estudio de la comunicación.

Puede parecer obvio ¿pero acaso múltiples artículos, investigaciones y publicaciones no indican que esta postura crítica es cada vez menor, mientras que se extiende un conjunto de estudios e investigaciones con tendencias tecnocráticas, prágmáticas, de descontextualización de la parte respecto al todo, acríticas respecto a los marcos políticos e ideológicos predominantes, que vuelan por diferentes galaxias teóricas sin nunca aterrizar en la realidad que dicen analizar e investigar, o despolitizadas de manera explícita o con una idea de política que conduce a la abstracción esteril o queda en un discurso lleno de palabras pero vacío de contenido?

Se trata, en definitiva, de analizar todas las facetas del sistema de comunicaciones pero en la realidad concreta en la que se ubican, entendiendo por ésta su estructura social, económica y política, sus emisores y receptores, los contenidos y marcos culturales que se transmiten y los intereses a los que sirven, etcétera.

El objetivo del presente trabajo es por lo tanto una evaluación de la realidad actual de los estudios e investigaciones en comunicación en nuestros tiempos neoliberales y posmodernos, con base en lo conocido de que "las teorías económicas no son meros diseños de estrategias técnicas: son, sin lugar a dudas, la expresión de concepciones éticas que afectan en su totalidad a la vida humana, a los lazos sociales y muy especialmente a las relaciones de poder" (Barenblit, 1997:13), y por tanto también inciden sobre los conocimientos -sobre todo los sociales-y las formas de encararlos, donde los de la comunicación no pueden ser ni son una excepción. Así como se hizo con otros modelos económicos y sociales (el capitalismo 
en general, el llamado "socialismo real", las corrientes funcionalistas, etcétera) buscando conocer y/o cuestionar sus perspectivas acerca de los medios de difusión y sus formas de estudiarlos, lo mismo debe hacerse con un modelo no solo convertido en hegemónico a nivel mundial y sin contrapesos, sino que también se llega a considerar como único camino e incluso como "fin de la historia". ${ }^{4}$

\section{Lo "viejo" que se mantiene}

Es muy conocido que lo "nuevo" es uno de los aspectos centrales y de culto del proceso de la modernidad, y no deja de serlo - al contrario, se agudiza - en los actuales momentos tanto "posmodernos" como neoliberales. Antes y hoy estar al día, o ser "moderno" o "posmoderno", significaba y significa tener y/o conocer lo "nuevo", término que cada vez más aparece en todo, desde en anuncios y etiquetas comerciales hasta en las temáticas de encuentros y eventos científicos.

Se trata de un fenómeno cuyas causas son demasiado conocidas, pero sí es necesario señalar cómo esto aumenta en una época que, dentro de las llamadas "ciencias sociales" y en general, se vive la multicitada "crisis de paradigmas", de crítica a los saberes existentes, y de caída o desvalorización de mitos y de verdades vistos antes como casi absolutos.

Y, por supuesto, también por un desarrollo de conocimientos y avances tecnológicos como nunca se dieron antes, con la consiguiente revolución que provocan en todos los campos y en las formas de vida, haciendo que lo nuevo tenga cada vez menor duración y pronto, muy pronto, se convierte en antiguo y obsoleto. Por supuesto no hace falta mostrarlo en el ámbito de una comunicación hoy sustancialmente diferente a la existente hace pocos años y que, por tanto, requiere de constantes nuevos estudios e investigaciones. Esto, por obvio y conocido, tampoco requiere de ninguna demostración: la simple fuerza de los hechos obliga a incorporar lo nuevo que constante y rápidamente se nos presenta.

4. El modelo neoliberal es suficientemente conocido como para señalar aquí su contenido, bastando recordar como su idea original surge en 1947 en una reunión de la Sociedad Mont Pèlerin con, entre otros, Milton Friedman, Karl Popper, Ludwig von Mises, Walter Lippman y Salvador de Madariaga. Hoy con distintas pero no antagónicas corrientes (la de Chicago, austríaca, la virginiana, el anarcocapitalismo) propugnan una economía del más amplio libre mercado, la expansión de los grandes capitales sin restricciones ni obligaciones sociales ni fiscales, lo que significa la desregulación de las economías precedentes, la privatización de las empresas estatales, el abatimiento de la crisis financiera con políticas recesivas y antiinflacionarias, la restricción de la oferta monetaria, etcétera. Sus mayores expresiones fueron los gobiernos de $\mathrm{M}$. Tatcher en Inglaterra y $\mathrm{R}$. Reagan en Estados Unidos, aunque en otros casos su aplicación ha tenido que adecuarse a las características específicas de cada país. 
Pero esta veloz renovación ¿anula la totalidad de los conocimientos que se adquirieron durantes las largas décadas de construcción de lo que hoy se llama, tal vez un poco pedantemente, "ciencias de la comunicación"? Sería absurdo afirmarlo con total certeza y para tódo: es cierto que muchas veces los nuevos saberes reemplazan, parcial o totalmente, a otros anteriores, y que las nuevas tecnologías obligan a ver de otra manera lo sabido con anterioridad. Pero también lo es que una muy importante cantidad de planteamientos anteriores, algunos incluso bastante antiguos, en el peor de los casos sólo requieren de actualización pero sin perder un valor que no sólo permanece sino incluso se acrecienta en los tiempos actuales. Aunque la moda presente acerca de lo "nuevo" no quiera verlos -0 afirme tenerlos en cuenta sin en realidad hacerlo- por razones no precisamente casuales ni inocentes que luego se mencionarán.

Los estudios sobre comunicación han sido tan fuertes e importantes en la América Latina de los sesenta y los setenta que hasta se consideró que formaron una "escuela" que estuvo notoriamente vinculada a los procesos políticos e ideológicos críticos y contestatarios de la época. Quienes la conozcan o recorran los múltiples materiales producidos - como parte de toda una tendencia general de ese período en el mundo entero- podrán observar que en ellos los medios de comunicación siempre estaban ubicados, desde una perspectiva clara y explícitamente crítica, en el contexto de la realidad económica y social de la época, con fundamentalmente dos ejes centrales sobre los que se colocaban y analizaban otros aspectos:

1) sus sistemas de propiedad y de control, tanto por su vinculación con los gobiernos y poderes locales dominantes, como por su relación con el control definido como "imperialista" de los mismos, es decir su dependencia de aspectos políticos y económicos del exterior, muy en particular de unos Estados Unidos que tenían un conocido peso hegemónico sobre los países del continente y del mundo;

2) los contenidos político-ideológicos que transmitian, considerando que ninguno era inocente sino que todas las programaciones (desde las informativas hasta las de diversiones e infantiles) eran ideológicamente expresión de la dominación política y económica, que buscaban mantener y acrecentar a través del "control de las conciencias" y de la "manipulación" de unos receptores que, salvo minorías, difícilmente podían acceder a otros contenidos. En este sentido se consideraba que los medios actúan como las más fuertes instituciones consolidadoras de la "realidad" existente, evitaban la presentación de otra cuestionante, presentaban las formas de vida existentes como las ideales, etcétera, para lo cual se impedía o reducía la difusión de todo aquello que negara lo anterior. 
No es este el lugar para recordar otros aspectos de tal corriente, como tampoco para destacar las diferentes críticas que se le hicieron en los años posteriores, críticas que hacian referencia a posturas unilaterales con a veces pocos matices o con ausencia de estudio de temáticas de gran importancia no incluídas, pero no al sentido general de lo planteado. Sin embargo, desde los años posteriores al apogeo de tal tendencia, pudo observarse desde un abandono parcial hasta algunos totales de tales planteamientos. Paulatinamente comenzaron a tener preeminencia nuevas formas de estudio y de intereses —entre ellas la semiótica y el análisis del discurso ya indicados, etcétera- como ocurrió de manera similar en prácticamente todos los campos de las ciencias sociales.

Es muy importante dejar en claro que no hay duda de que todo conocimiento requiere de la incorporación, permanente y constante, de todos los nuevos aspectos que vayan surgiendo, pero también requiere que se haga manteniendo y siempre actualizando lo que se mantenga válido de lo precedente. Lo "nuevo" debe entonces ser incorporado a lo "viejo", y éste ser modificado de acuerdo a lo reciente.

Con base en esta incuestionable premisa se plantea una pregunta central: ¿han cambiado las condiciones de los medios en el mundo entero como para abandonar los dos ejes estructurales antes citados, es decir lo relativo a los sistemas de propiedad de los mismos y de transmisión de determinados contenidos ideológicos y politicos? Y la respuesta es demasiado evidente: si bien puede decirse con razón que los cambios producidos en los medios de difusión han sido cuantitativa y cualitativamente muy amplios e incluso espectaculares, que por las nuevas tecnologías hay una oferta notoriamente superior a la de décadas pasadas, que en algunos casos -en particular Internet- ello implica una marcada apertura e incluso democratización respecto a los contenidos (al menos para los sectores que tienen acceso a tales novedades tecnológicas), es también evidente que los ejes centrales antes mencionados no sólo se mantienen sino que se han acrecentado en muy amplio grado.

Es demasiado conocido y no requiere demostrarse ahora que, de la misma manera que desde hace años se produce en todas las areas económicas del mundo entero cada vez más "globalizado", en el campo de las comunicaciones también existe un proceso de concentración de las empresas con fuerte peso e impacto, que a la vez también se da en escalas nacionales: han surgido así editoriales de un poder antes no conocido, se mantienen y crecen las agencias noticiosas de siempre, y ni hablar ya de las empresas del campo audiovisual e informático. ${ }^{5}$ Las que no se

5. Hace pocos meses la revista Proceso publicó una extensa nota donde Enrique Maza sintetiza un libro recién aparecido en Estados Unidos donde se muestra tal concentración, incluyendo 4 ejemplos de los 
inscriben en sus esferas de acción tienen un peso cada vez más reducido, y su importancia cuantitativa no puede compararse. ¿Qué puede hacer, por ejemplo y para dar sólo uno local , Radio Educación o la revista Proceso frente a la capacidad de llegada internacional de Time-Warner, CNN o similares, o dentro de México respecto a Televisa o TV Azteca (que, por otra parte, están cada vez más vinculadas -en términos económicos y en contenidos-a empresas trasnacionales)? Sin negar ni el valor ni la significación de los medios indicados y muchas otras similares, es evidente que se trata de enanos frente a mega-gigantes trasnacionales, causa por las que muchos medios similares son permitidos o tolerados para presentar una imagen de apertura que es sólo formal y limitada por causas evidentes, y que incluso pocas veces llega a la posibilidad de acceso a emisiones audiovisuales por su mayor penetración. ${ }^{6}$

En cuanto a contenidos el panorama es similar. Por supuesto es cierto que las posibilidades de acceso a cada vez mayor cantidad de programaciones y canales es real, pero también lo es que sólo se trata de variaciones de lo mismo en cuanto a significaciones $y$ visiones del mundo y de la vida. Tampoco aquí es necesario ofrecer ejemplos, para lo cual bastaría con recordar lo ofrecido sobre el conflicto del Golfo Pérsico y la ofensiva de la OTAN en Kosovo en información, y la muy baja apertura hoy existente respecto a visiones diferentes a las dominantes en el terreno ideológico y político.

Es que el mundo tiende cada vez más a un pensamiento único con la hegemonía de un modelo neoliberal que no vacila en considerar que con él se ha llegado al

12 considerados "grandes". Un claro y categórico ejemplo de algo muy viejo que hoy se extiende es el siguiente párrafo del citado artículo: "Chrysler invirtió 270 millones [de dólares] en publicidad, en 1996, sólo en revistas. A principios de 1997, el departamento de publicidad de Chrysler, envió esta carta a todas las revistas en las que se anunciaba: 'Se exige que la Corporación Chrysler sea avisada con anterioridad de cada uno y de todo contenido editorial que toque temas sexuales, políticos y sociales, y de todo contenido editorial que pueda ser interpretado como provocativo $u$ ofensivo. Se requiere previamente un sumario escrito que resuma los artículos importantes que aparezcan en todos y cada uno de los números de la revista que llevan la publicidad de Chryler'. Todas las revistas tenían que firmar un acuerdo al respecto. La censura previa de las corporaciones al contenido de la prensa libre. Lo mismo hacen, entre otros, Westinghouse y Procter and Gamble. Todo programa de la CBS y de la ABC, debe ser enviado a los anunciantes para su censura previa" (Maza, 2000:76).

6. Muy claros ejemplos al respecto es lo que ocurre en muchos países latinoamericanos que en palabras aceptan la vinculación economía de mercado/democracia, pero donde prácticamente nunca partidos y sectores no oficiales pueden acceder a la posesión de frecuencias de radio o de TV. En Chile no existe un solo medio, ni siquiera gráfico, de grupos de izquierda, y en México pasa lo mismo con emisoras de radio y TV. En Perú el acceso ni siquiera se da en las programaciones: el candidato presidencial opositor a Fujimori no pudo entrar a ningún canal de TV (con excepción de uno de cable de muy escasa audiencia). 
"fin de la historia", y los medios son representación de tal idea aunque mostrándolo de múltiples maneras pero coincidentes en el fondo. ${ }^{7}$

Es por tanto importante reconocer esta realidad sin caer en la trampa de apariencias tan brillantes como vacías. Lo que implica no confundir tal realidad con el maquillaje, ni quedar seducidos ante la fulgurancia de nuevas comunicaciones que efectivamente aportan múltiples elementos prometedores e incluso valiosos potencialmente, pero para seguir funcionando como lo han hecho clásicamente: como transmisores de los intereses de la dominación impidiendo la toma de conciencia de unas condiciones de existencia cada vez más conflictivas en todos los terrenos. ${ }^{8}$

Sin embargo el campo de estudio e investigación de la comunicación en muy importante medida ha caído en tal seducción, y si bien dificilmente alguien niegue algo de lo anterior -salvo, por supuesto, los defensores a ultranza de la hoy hegemónica "economía de mercado"-, es evidente que la primacía de preocupaciones se ubican en los terranos de "lo nuevo", al punto que en múltiples reuniones y encuentros estas problemáticas simplemente están ausentes como si no existieran, fueran cosas del pasado o temas "viejos". 9

Se trata entonces de ver las formas y caminos por los que el campo de la comunicación en amplia medida ha perdido el rumbo.

7. La literatura muchas veces ofrece visiones muy gráficas, tal como lo hace un conocido escritor checo que así como supo criticar al regimen antes imperante de su país también lo hace con los medios de una nación desarrollada: "Le doy vueltas al botón hasta llegar a la emisora más cercana, porque quiero provocar, en el sueño que se aproxima, imágenes más interesantes. En la emisora vecina una mujer anuncia que el día será caluroso, pesado, con tormentas, y yo me alegro de que tengamos en Francia tantas emisoras de radio y de que en todas se diga, exactamente en el mismo momento, lo mismo acerca de lo mismo. La unión armónica de la uniformidad y la libertad, ¿puede desear algo mejor la humanidad?". Y con la misma ironía escribe más adelante: "La emisora de radio que escucho pertenece al Estado, por eso no hay anuncios y entre noticia y noticia ponen las últimas canciones de éxito. La emisora de al lado es privada, así que la música es reemplazada por los anuncios, pero éstos se parecen a las canciones hasta tal punto que nunca sé que emisora estoy oyendo" (Kundera, 1990:14-111).

8. Sobre algunas de estas condiciones pueden verse una amplia cantidad de materiales. Desde la perspectiva de las consecuencias sobre el hombre de nuestro tiempo, mis artículos (Guinsberg, 1994, 1996c, 2000b).

9. Un claro ejemplo al respecto fue el "Primer Encuentro Nacional sobre la Enseñanza y la Investigación del Cine en México", organizada por AMIC, CONEICC y la UAM-X en 1996, tal como lo señalara en una ponencia alli presentada donde el tema sobre los ejes de los contenidos del cine de nuestros tiempos neoliberales y posmodernos tuvo que incluirse en otros por no haber un punto específico para el mismo (Guinsberg, 1997b). 


\section{¿De "críticos" a "integrados"?}

Ya se mencionó que no se trata de algo exclusivo de esta disciplina sino que es parte de una tendencia general de las preocupaciones académicas de nuestro tiempo, donde pareciera que el intelectual crítico ha perdido el papel clásico que ha tenido siempre en la historia, para convertirse, salvo excepciones, en "integrados" o con una postura sólo supuestamente "crítica" como se precisará más adelante.

En efecto, en tal contexto ha cambiado rotundamente el rol o papel del intelectual, que de fiscal o crítico (desde moderado a absoluto, pero crítico), hoy predominantemente ha perdido tal condición para adecuarse, e incluso defender, a las leyes (implícitas o explícitas) de la competencia, rendimiento, adecuación, etcétera, de una economía de mercado que no respeta, acepta ni le interesan las críticas y cuestionamientos de fondo por parte de quienes viven bajo su cobijo y subsidios (estatales o privados). Nunca como ahora ha predominado tanto el pensamiento "unidimensional" tal como lúcidamente lo describió Marcuse (1985), sea por tal disminución de crítica cuestionante, como porque una mayoría de la que hay (y se difunde) —como se verá más adelante - se ubica en los terrenos esterilizantes, deshistorizados e inocuos del peor de los discursos "posmodernos" de moda. El panorama es entonces tan desolador como lo destaca un lúcido crítico:

En toda época de transición entre una fase que se ha desplomado y otra que se ha impuesto pero cuyas formas y consecuencias no están claras debido a la polvareda no asentada del derrumbe siempre ha zozobrado la razón y los intelectuales, demasiado integrados en el viejo establishment y demasiado funcionales para el mismo, se suicidan fisica o culturalmente, se llaman a silencio o se refugian en el oportunismo para tratar de mimetizarse... Nuestro tiempo no es una excepción a esa regla... La deserción de los intelectuales que se niegan a tratar de entender las transformaciones sociales, económicas, culturales, institucionales y abandonan sin lucha viejas trincheras va unida con el intento de otros de ofrecer un perfil bajo y de aparecer sumisos para reconquistar, como sector o casta particular, un puesto en las clases gobernantes que éstas no les reconocen y que los pueblos les niegan (Almeyra, 2000:58).

Aunque en realidad esto último debería ser matizado y visto de otra manera: más allá de la verdad que el autor señala sobre el cada vez menor peso de los intelectuales frente al cada vez mayor de los medios de difusión masiva, los sectores del poder múltiples veces los reconocen, tratan de cooptarlos e incluso los estimulan cuando les son favorables o cuando sus críticas no les molestan o son poco eficientes para producir movilizaciones o cambios serios, críticas que en definitiva son utilizadas 
para mostrar la existencia de supuestas formas democráticas de las que se jacta el actual modelo hegemónico.

Pero lo que aquí interesa analizar no es el caso de quienes aceptan —en algunos casos amparados bajo la idea de que "hay que ser pragmáticos"- perder o disminuir el carácter de críticos, sino cómo esto se produce.

Una primera forma es simplemente la incorporación de campos de estudio que en las épocas antes citadas no eran importantes para las instituciones comunicológicas o bien estigmatizados por ellas por su vinculación a claros intereses empresariales, pero que hoy son aceptadas, lo que indica un evidente cambio, tal como lo destaca Martín-Barbero: "Poco a poco ha ido tomando fuerza una mirada que aparentando ser independiente de la del norte, de EUA, es en el fondo un remedo de lo que en el Norte se considera 'investigación avanzada'. Ahí donde América Latina puso lo mejor y más original de su esfuerzo en los años setenta y ochenta - lo que implicó la búsqueda de un nuevo Orden Informativo Internacional- hoy está siendo minado". Refiriéndose a la investigación piensa que esta opta por "salvarse" haciendo que "tome un rumbo cada vez más pragmático, menos inquietante, menos abierto, inspirándose en la demanda, no de la sociedad... Creo que están ganando aquellos que para Adorno sólo hacían investigación administrativa, que es la que se despliega hoy a través de la 'comunicación organizacional', 'empresarial', e incluso de buena parte del llamado 'periodismo de investigación' (en Renero, 1998:159-160).

Por supuesto que esto no es nada nuevo: de por sí siempre existió, pero sin el peso actual y, sobre todo, prácticamente marginado de unas instituciones volcadas hacia un pensamiento crítico notoriamente mayoritario, y dentro de las cuales esas tendencias y profesionales eran denunciados e incluso estigmatizados. El cambio comienza a darse con las modificaciones políticas continentales y mundiales - derrota de los planteos rebeldes y contestatarios, paulatino ascenso neoconservador, etcétera - que, como es evidente, es acompañado por importantes sectores comunicológicos que inician un proceso autocrítico donde, como ocurre tan a menudo, se cae en las clásicas contraposiciones donde fácilmente se pasa a una vertiente diferente y hasta contraria a la anterior. Por supuesto sin ser ni el primero ni único caso, puede verse como paradigmática la postura de un connotado investigador y dirigente de instituciones comunicológicas al criticar lo realizado y proponer otro camino: "La que está un poco en crisis es la investigación académica, porque ha utilizado categorías analíticas muy ligadas a los planteamientos del marxismo y a los de una teoría crítica procedente de la escuela de Frankfort, lo cual no siempre generó el tipo de conclusiones que ayudan al continente a avanzar en los procesos de comunicación. La investigación académica ha sido muy crítica y más denuncista que cons- 
tructiva. Se ha denunciado mucho, se ha construido poco" (Marques de Melo, 1991:9). Si bien es cierto que considera valiosa a la perspectiva crítica, a la que define como "relevante", y que "no propongo hacer una investigación apolítica y acrítica", también señaló la validez de otros caminos: "Latinoamérica ha avanzado muchísimo en la producción comunicacional. Los casos de Televisa en México y de la Red O'Globo en Brasil son notorios. Estas no sólo son experiencias de producción para el mercado nacional o latinoamericano, sino también para el internacional. La investigación hecha por las empresas es un trabajo valioso".

Si bien tal crítica y propuesta son parte de un debate necesario - de ese momento y de ahora-, es evidente que plantea algo distinto y muy acorde con los nuevos planteos de moda en la época y actuales (prioridad de los valores productivos, economía de mercado, etcétera) y sin la necesaria valoración de los sentidos e intereses de tal producción, lo que abría camino a lo que en definitiva ocurrió en importante grado: búsqueda de trabajo en la empresa privada y pérdida, en distintos grados, de perspectiva crítica, o bien la preeminencia del ya famoso "doble discurso", es decir trabajo productivo para las empresas y al servicio de éstas y los planteos neoliberales, y denuncia en ponencias académicas. ${ }^{10}$

Otro connotado investigador entendió claramente las causas y significaciones de tal propuesta, y lo señaló sin pelos en la lengua: "Yo respeto muchísimo los criterios de mi amigo Marques de Melo con quien discuto y peleo. Lo que pasa es que Marques ha hecho un viraje hacia posiciones... bueno, no sé como calificarlas pero mucho más moderadas", y luego de destacar algo vinculado a lo escrito en páginas anteriores de este artículo - "el cuadro latinoamericano en comunicaciones se ha ido agravando: todo lo que denunciamos hace treinta años está entre nosotros peor aún; la dependencia es más fuerte y la contaminación iconográfica es excesiva"remarca que "una parte relativamente importante de la investigación se ha ido a praderas más asoleadas, más tranquilas, más risueñas: la semiótica y cosas de ese tipo. Pienso que hace falta que hagamos de todo, pero... Hay un péndulo que va de la utopía a la ideología, y en este momento está a la derecha, de lado de la ideología o sea del pensamiento que refuerza el estatus" (Pasquali, 1993: 20-21). El retroceso y el paso a posturas más conformistas, así como la pérdida de posturas críticas es también remarcado por quien señala que "entre los intelectuales de nuestros países (no sólo entre los investigadores en comunicación) hay un movimiento hacia atrás, el evidente error en el que supuestamente algunos incurrimos en el pasado; en vez

10. A veces tal "doble mensaje" es más oportunista todavia: si se trata de encuentros críticos se llevan ponencias (más o menos) críticas, y si se trata de encuentros de otro tipo se llevan las experiencias de trabajo donde tal crítica está ausente. 
de mantenerse criticos frente a una sociedad injusta se han plegado al otro bando", reiterando la necesidad de "rescatar un espíritu crítico, un espíritu no conformista" y remarcando que "el horizonte es de derrota en el sentido global; la única opción es, tal vez, el gran esfuerzo por una lucidez del espíritu e inteligencia; propongo pues no dejarnos avasallar" (Schmucler: 1993:22-23).

Por supuesto no son los únicos en reconocer tales pasos hacia, en las palabras de Pasquali, zonas más asoleadas y risueñas: "La proliferación de la investigación experta al servicio de la demanda empresarial y de las conexiones entre universidad y empresa ha creado otras relaciones de fuerza con la investigación crítica, cuya misión debería ser construir una mirada distanciada frente al pragmatismo managerial. (Lo que de ninguna manera implica aislarse de estas nuevas realidades. Bien, al contrario, ya que se trata de plantearlas como problemáticas)" (Mattelart, 1994:20). A su vez, y bajo el título de "La investigación de la comunicación en tiempos del libre comercio", otro investigar destaca esta realidad e indica sus formas:

Debido al cultivo de la tendencia altamente mercantilista y pragmática que ha caracterizado el desarrollo de la estructura cultural del modelo neoliberal en México y América Latina, al final de la década de los ochenta y principios de los noventa, se ha acentuado la dinámica de desproteger e incluso desaparecer la investigación de la comunicación de carácter humanista y social; y se ha impulsado desde las políticas oficiales científicas y educativas de los Estados nacionales latinoamericanas hasta los estudios tecnológicos, pragmáticos y eficientistas de la información. En este sentido, por ejemplo, han surgido en la región las investigaciones sobre las características fisicas de las nuevas tecnologías de la información, la ampliación de la televisión directa, la introducción de Internet, la expansión de los satélites, el empleo de las nuevas computadoras, el estudio de las intertextualidades, el examen del ciberespacio, la interacción de las máquinas de información de la última generación, el examen de la adaptación de los medios virtuales, la reflexión sobre la interconectividad, etcétera; y se ha descuidado u olvidado drásticamente el análisis elemental de los procesos de democratización de los medios de comunicación, el empleo de las nuevas tecnologías para impulsar el desarrollo social, el uso de las infraestructuras informativas para defender la ecología, el empleo de los medios para producir alimentos, el aprovechamiento de dichas tecnologías para reducir la violencia... De esta forma, con el lugar estratégico que el nuevo modelo de desarrollo modernizador le ha concedido al mercado para ser el eje fundamental que dirija y modele a los procesos sociales y educativos de América Latina, éste se ha convertido en el condicionante y el disparador central del cual se ha derivado el origen, el sentido y el destino de la producción cultural, comunicativa en nuestros países, en especial de la investigación de la comunicación(Esteinou, 1997:246-247). 
Una aclaración necesaria sobre esto último: si bien es correcto y preciso el señalamiento de que tal elección de temas de investigación y no interés por otros es muy significativa y un verdadero analizador (en el sentido que le da el análisis institucional a este término, similar al de síntoma), también es necesario dejar claramente establecido que la investigación sobre las nuevas problemáticas de la comunicación no sólo es útil sino imprescindible para comprensión de todo lo nuevo que aparece y tiene fuertes impactos sobre nuestra cambiante realidad. El problema no es por tanto tal elección - aunque se reitera que de por sí es significativa- sino cuando el estudio se hace prescindiendo del contexto social y politico en que se ubican, con ausencia de perspectiva crítica (en el sentido de evaluación de sus sentidos), con prescindencia de sus consecuencias y de la significación de sus usos, o viendo lo nuevo de la comunicación como lo pretende la ideología de la dominación, es decir como salida o vía de solución a los conflictos individuales, sociales, politicos y al "malestar en nuestra cultura".

Esto último parece convertirse en cada vez más extendido en la disciplina comunicativa, cayéndose en algo similar a lo que justamente se criticaba a los estudios estructural-funcionalistas, muchas veces llenos de datos de todo tipo pero descontextualizados. E impregna incluso a no pocos campos de investigación redescubiertos, entre ellos a estudios acerca de los procesos de recepción, convertidos en una de las nuevas "modas", pero también víctimas de estas tendencias, con lo cual su importancia y validez se desmerece. Varios son los caminos utilizados para ello: el primero, y posiblemente el más seguido, es ver tales procesos aislados del proceso de emisión, su obvia y dialéctica contraparte, con lo cual se los convierte en procesos individuales o grupales pero aislados de los contenidos que se reciben, con lo cual se rompe la unidad del proceso y, de paso, se olvida el análisis de que se pretende con los mensajes (Guinsberg, 1990a, 1990b, 1991b, 1996a, 1998). Como comprende Michèle Mattelart, "la tensión entre entre ese nuevo episteme de la vuelta al receptor, del reconocimiento del receptor como sujeto dotado de una cierta 'libertad', y todos los esfuerzos por cercenar esa libertad que se ponen en evidencia cuando se analizan las estrategias del poder tecnológico y de la mercantilización de la cultura, cada vez más apoyadas sobre las ciencias de la organización y del control; esas dos realidades coexisten, y hay que saber vivir lúcidamente la tensión de asumir ambas, sin caer en 'modas' que parcializan y fragmentan el análisis" (Kaplun, 1988: 61, subrayado mío). " Pero también dando tanta autonomía a la ca-

11. A lo que agrega Armand Mattelart en la misma entrevista: "Cuando se estudia el rediseño de las estrategias industriales y de mercado, se comprueba que esa 'vuelta al consumidor' está profundamente inscripta en la lógica de la reestructuración del capitalismo que, ante la crisis de su modo de 
pacidad de elección de los receptores que se disminuye notoriamente el poder de los medios (Schiller, 1992; Mattelart, 1998:111).

\section{Cultura-comunicación y sus vicisitudes}

Por supuesto no es nada nuevo que lo que puede ser un importante e incluso fundamental "cambio de paradigmas" según Kuhn, o "ruptura epistemológica" para Bachelard, se convierta luego - no por sus valores sino por su mal uso, exageraciones o fuertes distorsiones- en lo contrario de lo que pretendía. Algo de esto ocurre con mucho, no con todo, lo que hoy se cobija bajo las relaciones entre comunicación y cultura.

Que la comunicación es parte de toda cultura - en el amplio sentido antropológico del término- es algo tan obvio que hoy cuesta pensar que alguna vez no se lo viera así. ${ }^{12}$ De por sí "la comunicación, a diferencia de otras disciplinas u objetos de estudio, es a la vez que paradigma, campo interdisciplinario, fenómeno, práctica o conjunto de prácticas, proceso y resultado, parte esencial de la cultura y la innovación cultural, soporte simbólico y material de intercambio social en su conjunto" (Orozco, 1997:28). Pero no es sólo un campo interdisciplinario sino que lo que estudia es parte inseparable de todas las relaciones sociales, una especie de sintesis en el sentido hegeliano-marxista. En palabras de uno de sus principales exponentes: "El campo de los problemas de comunicación en América Latina reveló muy pronto su imposibilidad de limitarse y constreñirse a ser una teoría que dejara fuera las prácticas sociales de comunicación, esto es, los espacios, los procesos y los actores de la comunicación... Lo que se estaba planteando era la necesidad de ubicar el estudio

producción -crisis económica y política a la vez-, necesita un acercamiento cada vez más estrecho entre el momento de la producción y el momento del consumo. Diría incluso que lo ideal para él sería el poder fundir esos dos momentos en uno solo". Y en un texto posterior es aún más categórico y claro: "La apuesta mayor én los estudios de la recepción es no mitificar este campo y amplificar exageradamente el poder de los usuarios, sobredimensionando el valor del cara a cara negociado entre la oferta y la demanda. El riesgo es pasar de una concepción determinista de un consumidor abstracto, sin voz propia, sometido al imperativo de una estructura, emisor no menos abstracto, que caracterizó al estructuralismo de los años sesenta y setenta, a un receptor tan concreto que se olvida en qué sociedad y cultura vive. Dicho de otra manera, el riesgo consiste en volver al concepto de individuo que corresponde a los viejos empirismos" (Mattelart, 1994:24).

12. En realidad siempre se lo vió así -al menos por parte de las principales corrientes comunicológicas latinoamericanas y todas las que, como la Escuela Frankfort y tantas otras, partían de planteos marxistas o sociológico- pero con significaciones distintas a lo que hoy se entiende así y que se verá párrafos más adelante. Recuérdese que una muy importante revista transhumante por razones políticas —nace en Chile, pasa a Argentina y termina en México-, que nace en 1973 y dura hasta 1985, se llamó Comunicación y Cultura. 
de los medios mismos en las redes de comunicación cotidiana de la gente, en la inserción de la influencia misma de los medios en el vivir, en el soñar y en el trabajar de la gente. Sin duda esto suponía, como planteé también en un artículo, olvidarnos del objeto para pensar en los procesos. Es indudable que si el único objeto de estudio de la comunicación son los medios, resulta muy difícil pensar en los autores, los sujetos y los procesos" (Martín-Barbero, en Montoya, 1993:36).

$\mathrm{Y}$ parece que de golpe todos descubren que es así y los principales exponentes de este nuevo camino se convierten en los nuevos "gurús" de la comunicación, centros absolutos de la mayor parte de los principales encuentros latinoamericanos aunque muchos de ellos no se definan ni reconozcan como comunicólogos. La comprensión de "la comunicación como parte de la cultura" se convierte en una especie de nueva Biblia por sus seguidores, y la noción de "mediaciones" en algo así como su profeta. ${ }^{13}$

El problema no es el enfoque originario sino sus posteriores distorsiones, y los responsables tampoco sus pioneros que, como se verá después, en importante medida reconocen lo que ocurre. Tampoco quienes sensatamente y con claro conocimiento de él recorren un camino que consideran productivo, pero sí los clásicos seguidores de modas y constantes repetidores que esterilizan lo válido amparándose en generalidades donde todo se convierte en "cultura" y en "comunicación", perdiéndose toda especificidad en una vaga nebulosa donde todo entra: $i$ acaso puede negarse que el ser humano siempre es cultura o está atravesado por ella y que, igualmente, todo vínculo humano es comunicación? Y si a esto se agregan, como ocurre, todas las tendencias y posturas actuales sobre rupturas de límites disciplinarios, intertextualidades, metodologías cualitativas e infinitos planteos sobre todo surgidos de variantes "posmodernas" generalmente entendidas como se quiere, es comprensible que por comunicación-cultura también se entienda lo que se quiere.

Por supuesto que es cierto que "hasta la fecha no conocemos un marco disciplinario que pueda llamarse la ciencia de la comunicación, a pesar de que haya una multiplicidad de teorías de la comunicación... No tenemos entonces, ni hemos tenido hasta ahora (una) disciplina, sino un campo problemático, a partir del que ha ocurrido la generación histórica de un campo sociocultural", por lo que "de todo lo

13. "La comodidad con la que hoy, por ejemplo, se utiliza en los discursos académicos de la comunicación la noción de 'mediación', es sospechosa. Pocos estudios se toman el trabajo de explicitar desde dónde y cómo se utiliza; como si la noción por sí misma fuera portadora de su propia explicación o como si hubiera una especie de acuerdo tácito que volviera innecesario cualquier tipo de discusión" (Reguillo, 1997:135). Uso semejante al de otras palabras con connotaciones misticas que pretenden explicar todo al ser utilizadas por quienes no las manejan, como "dialéctica" para marxistas o "inconsciente" para psicoanalistas que toman a estas valiosas escuelas como "religiones laicas" (Guinsberg, 1996b). 
anterior se deriva una primera serie de retos fundamentales para quienes 'poblamos' este campo sociocultural de la investigación de la comunicación. Uno es reconocer, y asumir como reto, que no tenemos, ni hemos tenido, un campo disciplinar propio, sino un dominio de estudio, más o menos común, alrededor del cual se ha conformado nuestro campo sociocultural. Y dos, que este dominio ha sido, es y quizá tendrá que seguir siendo, una encrucijada inter y transdisciplinaria, dentro de las ciencias sociales y humanidades, lo que hace el reto aún mayor, en la medida en que exige de cada uno — dependiendo de los objetos más específicos de investigación-, el desarrollo de un amplio espectro de capacidades teóricas y metodológicas". Para quien escribe lo anterior (Sánchez Ruiz, 1997:55 a 57) “es mejor así, para no esquematizar y simplificar la enorme riqueza y complejidad de las múltiples formas y niveles posibles de comunicación entre los humanos", lo que puede ser adecuado y correcto, siempre que en tal amplitud y encrucijada inter y transdiciplinaria aparezca al menos un objeto de estudio similar, aunque sea con todas las variantes que se quiera, y no un campo sin límites donde todo pueda entrar en nombre de que no hay nada que no sea o no se vincule con "cultura" y con "comunicación".

Es evidente la dificultad para definir los límites y pertinencias de tal campo, e indudablemente la discusión al respecto será tan larga como conflictiva. Aceptando como un importante avance el reconocimiento, teórico y en los hechos, de la comprensión de la necesidad de ruptura con las estrecheces de las disciplinas en general $^{14}$-máxime en un campo como el de la comunicación por las causas señaladas-, también resulta obvia la necesidad de al menos una cierta delimitación, que podría ser tan genérica como la del estudio de los medios masivos de difusión $y$ todos sus impactos. ¿Pero ocurre al menos esto en las investigaciones cuestionadas? No sólo no se observa en algunos ensayos y artículos, sino a veces en publicaciones completas, algunas de las cuales -como se verá más adelante- son producto de instituciones de comunicación que siguen la corriente de vinculación indicada. En no pocos casos el cambio parte de lo señalado de integrar comunicación con cultura, pero poco a poco, $o$ incluso abruptamente, lo primero desaparece o es sólo un punto de partida para estudios antropológicos o sobre la cultura de nuestro tiempo o incluso sobre cualquier cosa.

14. "Justamente la condensación y oclusión interdisciplinar que los problemas ofrecen en nuestra época son las que inclinan a acoger la exhortación de Russel Ackoff: 'debemos dejar de actuar como si la naturaleza estuviese organizada en disciplinas del mismo modo como lo están las universidades'. En efecto, frente a la complicación de nuestro tiempo, es importante intentar alcanzar a algún nivel -en el curso de las investigaciones - la conciencia, aunque sea elemental, de que nuestros problemas de especialistas constituyen articulaciones de un problema general y común, como nuestros destinos" (Cerroni, 1973:10). 
Así ocurre en una importante cantidad de "los llamados 'estudios culturales', los cuales han pasado - a partir de Martín-Barbero, vía García Canclini y Renato Ortíz, entre otros-, a gozar de clara hegemonía en tal campo [de la comunicación]", a lo que este autor agrega críticamente en coincidencia con lo señalado anteriormente, aunque algunos de sus conceptos son discutibles (entre ellos lo relativo a lo "nuevo" de la existencia de comunicólogos y la conclusión final del siguiente párrafo que debe ser matizada): "Algunos de los inconvenientes que podemos adscribir a tales estudios, se relacionan con su inespecificidad epistemológica. No son -mayoritariamenteestudios sobre comunicación. En realidad, tampoco son realizados por comunicólogos, lo cual es inevitable dado que estos se han formado sólo en generaciones muy recientes. De modo que filósofos, antropólogos, literatos, semiólogos, son los que están habilitados con palabra legitimada en este espacio. Ello ha redundado en una notoria inespecificidad discursiva, de manera que pareciera que es función de la comunicología estudiar simplemente la cultura. Estudios que se presentan a congresos de la especialidad, podrían formar parte de jornadas de antropología por ejemplo, sin aditamento alguno. Alguien dirá que se trata de una saludable superación de las barreras discipinares, pero entendemos que para que estas sean superadas, tendrían previamente que haber sido dibujadas. No se supera lo que no existe". Y agrega algo tan claro y evidente que sorprende que tenga que ser dicha, lo que es otro analizador de la situación que se vive en el campo de la comunicación: "No se trata, entonces, de que los estudios culturales no sean pertinentes, sino de fijar en qué consiste su pertinencia. De manera que se los entienda como un insumo imprescindible, pero luego sean aplicados a una especificidad que desborda la sola apelación antropológica. De lo contrario, nada se gana con consultar a un comunicólogo en relación a lo que uno recibiría de un sociólogo, por ejemplo: diluída la singularidad disciplinar, no habría nada especial para decir desde ella" (Follari, 1999).

A todo lo anterior deben sumarse por lo menos otros dos aspectos que contribuyen a que los estudios sobre comunicación tengan hoy unas características que, en demasiados casos, los alejan de la realidad concreta: una difusa concepción de política y una tendencia hoy acrecentada hacia un tipo de discurso genérico e incluso más literario-subjetivo que con bases sólidas metodológicas y de investigación. Ambos prototípicos de nuestro tiempo y de algunas tendencias de la cultura y ciertas modas "posmodernas".

Es conocido que la idea de politica y de su importancia ha cambiado notoriamente en los últimos años, tanto por las crisis teóricas antes señaladas, por el desengaño generalizado hacia los sistemas dominantes actuales y pasados, pero también por la actitud al respecto del modelo neoliberal hegemónico y de posturas posmodernas 
que, en una relación muy compleja, se vinculan al mismo no por ser parte de él sino por ser útiles a las posturas neoconservadoras.

Se trata de un tema sin duda dificil de analizar aquí por su extensión, pero lo planteado en páginas anteriores respecto a cómo muchos artículos e investigaciones se "olvidan" de ver todo lo nuevo y actual en sus dimensiones y significaciones políticas para priorizar otros aspectos seguramente menos importantes, es un elemento muy significativo e incluso concluyente (aunque muchas veces se justifique esa ausencia por considerarlo obvio, etcétera, lo que no cambia la situación). Si por parte de las posturas neoliberales la "política" es un aspecto secundario que debe ser minimizado porque lo centralmente importante es la economía de mercado que se auto-regula y el manejo técnico de todo (que eliminaria los vicios políticos), ${ }^{15}$ por parte de los sectores comunicológicos aquí cuestionados o también se cae - aunque de hecho, o sea no con los mismos fundamentos, pero los aspectos políticos desaparecen o se minimizan, como en el ejemplo apuntado al inicio de este párrafo-, o la idea de política es tan amplia que en ella entra prácticamente todo, lo que si bien puede ser teóricamente válido - recordemos aquí los planteos teóricos de Foucault al respecto-, ${ }^{16}$ también es utilizado para un no casual "olvido" de las relaciones y prácticas concretas de cada realidad concreta. De esta manera, como todo es político mágicamente desaparece lo político especifico.

No es entonces nada casual que diferentes investigadores señalen y cuestionen tal ausencia. Tomando sólo dos ejemplos como muestra representativa de un universo más amplio, en este sentido es tan interesante como polémica y contundente la crítica de una investigadora brasileña: "La pretendida ruptura con el enfoque ideológico de los fenómenos de comunicación (léase Escuela de Frankfurt y análisis semiológico) que marcó la investigación de los años setenta, parece haber 'vacunado' al modelo de las mediaciones contra la preocupación por analizar la dominación politica e ideológica de la comunicación, al desplazar el eje de la problemática de la comunicación hacia la esfera de la cultura y la subjetividad. Se ve claro el paso de la sociología política y la semiótica hacia la antropología y la psico-

15. Más allá de la equívoca separación que cada vez se hace más entre "políticos" y "tecnócratas" (como si estos últimos fuesen neutros política e ideológicamente), es muy interesante observar la acusación constante de sectores neoliberales de que tal o cual aspecto de la realidad "fue politizado": así ocurrió últimamente en México con la huelga de la UNAM, el caso Fobaproa y su manejo legislativo y por partidos políticos, la confección del presupuesto nacional, etcétera - podrian darse múltiples ejemplos más- ¡cómo si no se tratasen de problemáticas y decisiones esencialmente políticas en el sentido más absoluto del término!

16. Pero no sólo teórico sino también prácticos, ya que Foucault siempre tuvo - no sólo ante la lucha de liberación argelina - una postura clara y comprometida frente a las circunstancias de su época. 
logía como disciplinas básicas en el análisis de las mediaciones... El centrar el análisis en la relación sujeto-prácticas culturales, provoca disolución en las categorías politicas del poder, esto es, de los nexos teóricos entre las esferas política y cultural del ejercicio del poder en las prácticas cotidianas" (Vasallo de Lopes, 1995: 88-90). ${ }^{17}$

Igualmente es claro, contundente y también irónico otro connotado investigador:

Hace unos años estuve en Bruselas en una reunión sobre tecnologías de la información. Me llamó mucho la atención que en los dos días de debate nunca apareciera la palabra ideologia. Al acabar, en el aeropuerto me encontré a Umberto Eco y le comenté esa sensación. Eco se puso a reir y me dijo: 'bueno, a lo mejor dentro de un tiempo ni siquiera se hablará de cultura'. Creo que estamos asistiendo al inicio de un proceso en el que el interés por el fenómeno de la comunicación es cada vez más económico-tecnológico. Sobre todo desde la experiencia que estamos viviendo en Europa y en los países más desarrollados del mundo. El enorme interés social es mucho más fuerte desde esas perspectivas que desde el punto de vista ideológico. Y esto es un signo de las nuevas formas de poder en la sociedad actual' (De Moragas, 1997:76; subrayado mío).

El propio Martín-Barbero reconoce que hubo distorsiones en el manejo de su planteo sobre mediaciones e incluso que "hubo un uso perverso del libro, especialmente en México", preocupándole, aunque sin sentirse responsable, el "manejo de las mediaciones como moda". Pero también, lo que es muy importante es que entre otras evaluaciones acerca de su obra afirma que "se hizo una lectura que no tiene

17. La misma autora agrega algo importante: "Tal vez sea en el tratamiento que da al concepto de clases donde el modelo de las mediaciones demuestre una limitación más seria en su esfuerzo por adecuarse metodológicamente al análisis de una realidad histórico-social como la latinoamericana. De hecho, si la prueba crucial para una teoría radica en la validación extrema de su discurso por su 'tiempo histórico' y en la homología entre su movimiento interno y el curso del mundo; si las sociedades latinoamericanas, en particular la brasileña, nunca mostraron desniveles tan grandes entre las clases sociales, es de extrañarse el abandono o la disolución del concepto de clase social por el modelo de las mediaciones" (p. 90). Dos aclaraciones: la primera respecto a la afirmación sobre la psicología, que puede brindar aportes muy útiles para comunicación (Guinsberg, 1986), siempre que no se caiga en un "psicologismo" negador de la incidencia de lo social-político sobre el psiquismo tal como se destaca en mis trabajos donde encaro tal vinculación y en las criticas a tal ausencia de también entender a lo subjetivo como afectado por lo social-político; la segunda a que tal crítica es también válida para otras posturas comunicológicas actuales, además de que no debe sorprender tal negación del concepto de clase social en múltiples marcos teóricos que han tirado por la borda no sólo las excrecencias del marxismo dogmático y totalitario sino todo lo que ha surgido de él, entre ellas la idea de ideología, dialéctica, etcétera; en el caso concreto de clases sociales prefiriendo las nociones norteamericanas de status, sectores sociales en sentido general, etcétera. 
nada que ver con el libro, como la de que los medios no son tan importantes", lo que niega tajantemente, así como que "yo no negaba la manipulación ni lo que su estudio aportó" ni lo que considera fundamental: "no digo que no sigamos estudiando las propiedades de los medios o lo contenidos o las estructuras de significación; lo que estoy diciendo es que todo esto tiene que ser puesto en la perspectiva de cómo la gente se apropia de los medios: para qué los usa". Destaca también que "sí necesitamos teoría de la comunicación, es decir que se configure un objeto de reflexión y análisis particular", aunque considerando que tal necesidad "no es equivalente a convertir la comunicación en una disciplina" ni en un sustituto de la acción social (Saintout, 1998:36-37). Aclaraciones necesarias para un imprescindible deslinde del "uso perverso" al que se refirió.

\section{Otros usos "perversos"}

Los límites de espacio impiden el desarrollo necesario de otros dos "usos perversos" en el campo de la comunicación: la utilización de la "teoría del discurso" y las disquisiciones "subjetivistas" en lugar del análisis fundamentado.

En cuanto al discurso por supuesto que no se niega la importancia del lenguaje y del análisis de la escritura, sino todo lo contrario. Lo que se cuestiona es cuando se lo absolutiza incluso se lo sacraliza y convierte casi, aunque sin decirlo así, en hecho dominante y unicausal, que a la vez sirve para tapar, negar u olvidar otros importantes $e$ incluso fundamentales factores como los ya señalados. Por el contrario, muchos autores no casualmente refuerzan la idea de que "las formas simbólicas se insertan también en contextos sociales e históricos de diversos tipos"y que "la hermenéutica nos recuerda que los sujetos que en parte constituyen el mundo social se insertan siempre en tradiciones históricas" (Thompson, 1993:299303). O dicho aún más claramente, "adentrarnos en el terreno del discurso implica no dejar de lado el contexto social que lo surca, pues no existen elaboraciones discursivas ahistóricas ni mucho menos neutrales"(Bonilla, 1995:88). Claro, parece algo de perogrullo y nadie lo negará, ¿pero acaso en múltiples casos no se hace lo contrario, cayéndose en la delectación por una especie de juegos donde se rumian los detalles más minuciosos con prescindencia de todo contexto, o en otros escribiéndose sesudos textos semióticos para demostrar lo obvio?

En cuanto a lo de las "tendencias subjetivas" se encuentra intimamente vinculado a todo lo anterior. En efecto, frente a la muy posmoderna "crisis de los metarrelatos" surge la propuesta de que no hay verdades absolutas y deben abrirse los 
campos del pensamiento y escucharse todo prácticamente sin limitaciones, lo que a su vez permite una apertura a los planteos subjetivos de todo tipo. ¿Cómo cuestionar y no apoyar algo tan fundamental, máxime cuando es algo que siempre debería haber existido pero que se resalta como reacción a la sacralización de algunas teorías predominantes en el último siglo pese a que éste se enorgullecía de la vigencia de su racionalidad?; ¿cómo incluso no reconocer la importancia del reconocimiento de diversidades antes negadas o minusvalorizadas (caso del género, la sexualidad, etcétera)?

Pero, como tantas veces ocurre, es muy fácil el paso a todo tipo de excesos y, en este caso, de igualaciones forzadas, que ha llegado a que el "conocimiento" actual en ciencias sociales se asemeje a la irónica letra de un muy famoso tango, ${ }^{18}$ donde por tanto todo es válido y permitido sin muchas veces importar la justificación de lo que se dice y/o hace. Tal vinculación entre relativismo y planteos subjetivos ha permitido, posibilitado e incluso "legalizado" desde obras e ideas valiosas o al menos interesantes hasta la más absoluta y cruda charlatanería, pero lamentable aunque inexorablemente esto último ha prevalecido respecto a lo primero: es claramente perceptible una tendencia, hoy vigorosa y multipresente, de tal seducción por el lenguaje y sus juegos con él, muchas veces - las más - priorizando tales usos sobre los contenidos, haciendo creer (por supuesto no a todos) que ellos encierran "profundidades" y "sutilezas" no siempre, o pocas veces, existentes (como ocurría en esa excelente película Un jardinero con suerte), o mediante la apelación a las frases de fuerte efecto pero con similar vaciedad. Algo así como lo que Lipovetzky definió, en otro sentido, como La era del vacio (pero recubierto de formas y apariencias). $O$ de quien escribe que "crean en el proceso de recepción un ambiente en el cual unos adeptos hablan a otros adeptos; es un lenguaje para los pocos sabios, para los discípulos de un círculo, para los que forman parte de este proceso, para los que están a la escucha piadosamente [y] los gurús hablan a los que ya han sido convertidos" (Becker, 1994:20).

¡Cuánto de todo esto se observa en textos, conferencias y cursos hoy predominantes! ¡Cuánto de lo que se ve es parte de algo que surge de la teoria del discurso, para convertirse en simple "discurso" a secas (en el sentido peyorativo de los similares términos mexicano "rollo" y argentino "guitarreo") !Y que también muchas veces es leído o escuchado con un verdadero arrobo casi hipnótico pese a que

18. Hoy resulta que es lo mismo ser derecho que traidor, / ignorante, sabio, "chorro", generoso o estafador, / todo es igual, nada es mejor, / lo mismo un burro que un gran profesor. / no hay "aplazaos", ni escalafón, / los inmorales nos han igualao. "Cambalache" de Enrique Santos Discépolo, creado en 1932 como descripción de la corrupción y el "fraude patriótico" fomentados por el regimen militar que derrocó al gobierno democrático de Irigoyen en 1930. 
se diga poco o nada, o se inventen cosas "sacadas de la manga" gracias a una capacidad altamente imaginativa y de seducción, más aún si se apoya en un importante nivel de conocimiento y de fuentes bibliográficas, lo que hace creer en su validez o en la capacidad de quien lo hace de "ver lo que otros no ven", quienes incluso utilizan un "terrorismo intelectual" de desprecio a quienes no entran en el juego con base en la una idea de "superioridad" que muchas veces poseen quienes consideran tener la verdad por "estar de moda". Esto puede hacerse, y se hace, con cualquier tema en un momento donde, ante tales desplantes imaginativos es posible hasta "extrañar" - ia que extremos hemos caído! - esa innecesaria multiplicidad de estadísticas de que hace gala el funcionalismo norteamericano, generalmente poco útiles - no siempre, hay excepciones- para una comprensión de lo que se estudia, pero al menos indicativas de alguna base de investigación.

Ante tales situaciones, ¿cómo no compartir las afirmaciones de Sokal y de Brincman cuando ven en tales especulaciones que "lo que se presenta como "ciencia' [aunque en estos casos no se pretende esto sino otra cosa, que igualmente consideran válido y valioso] es un cóctel de confusiones monumentales y fantasías delirantes", o "un bloque de logorrea [que] hasta donde alcanzamos a ver no significa absolutamente nada", y destacando la "enome diferencia entre los discursos que son de difícil acceso por la propia naturaleza del tema tratado y aquellos en que la oscuridad deliberada de la prosa oculta cuidadosamente la vacuidad o la banalidad"? (Sokal y Brincman, 1999:169-174-205).

La referencia al posmodernismo por supuesto no es casual sino muy intencional. Más allá de lo que ésta sea y sus sentidos polisémicos, sus significados afectan a la cultura en general: crítica a la modernidad en lo referente a las promesas de la razón y del progreso, incremento del desencanto de todo y ante todo, preminencia de lo individual y subjetivo frente a lo social y colectivo, rechazo de la historia como posible progreso y liberación, reivindicación y defensa del libre y múltiple pensar frente a una razón uniforme y universal, ultravaloración del discurso, caída de los metarrelatos, etcétera.

Mucho de eso es o puede ser válido - ¿cómo, por ejemplo, no aceptar muchas de sus críticas a la modernidad y no defender la libertad de pensamiento cuando son conocidas las consecuencias de todas las posturas dogmáticas?-, pero también debe verse a donde llevan esas posiciones y qué postulan en su lugar. Y el resultado es tan triste como lamentable, como puede verse en la muy amplia bibliografia que se ha producido y produce en esa perspectiva: vuelo en la galaxia sin aterrizar casi nunca en ningún lugar concreto, discursos tan complejos como vacíos, ausencia de toda referencia histórica y social específica aunque se diga hacerlo, preeminencia 
del discurso florido sin mayor contenido, análisis esencialmente subjetivos sin base de apoyo que lo justifique, desencanto absoluto y negación de aunque sea mínimas salidas, etcétera. O, como escriben Sokal y Brincman, "la fascinación por los discursos oscuros, el relativismo epistémico unido a un escepticismo generalizado respecto de la ciencia moderna, el interés excesivo por las creencias subjetivas independientemente de su veracidad o falsedad, y el énfasis en el discurso y el lenguaje, en oposición a los hechos a que aluden, o, peor aún, el rechazo de la idea misma de la existencia de unos hechos a los que es posible referirse" (Sokal y Brincman, 1999:202).

Claro que puede decirse que el posmodernismo es, o puede ser, otra cosa. Y puede serlo al menos teóricamente y a veces lo es pero demasiadas veces coincide con los planteos neoliberales hegemónicos en el mundo y no pocas veces le sirven como coartada ideológica aunque no sea su intención. En este sentido es muy recomendable la lectura de un texto de un conocido intelectual (que hace poco fue Secretario General de la Presidencia de Chile) que no duda en considerar al posmodernismo como contraparte del que llama "capitalismo posindustrial" (Brünner, 1998), aunque otros son menos categóricos pero ven clara la vinculación: observan que lo posmoderno no es sinónimo de neoconservador al tratarse de dos fenómenos diferentes, pero entienden que "muchos rasgos posmodernos resultan funcionales a las políticas de dominación" al ayudar a la debilidad de la sociedad civil y a la capacidad de resistencia (Follari, 1993:79). En similar perspectiva Hopenhayn señala las conexiones entre las críticas posmodernas y el proyecto de hegemonía cultural neoliberal: a) la exaltación de la diversidad redunda en la exaltación del mercado, donde la desregulación es el correlato práctico de la multidiversidad; b) la crítica de las vanguardias se traduce en una crítica de la política (salvo que esta esté a favor de la desregulación) y de cualquier planificación e intervención estatal; c) no habiendo una dinámica emancipadora que corra por debajo de los acontecimientos, nada permite cuestionar la sociedad de consumo, el derroche, la alienación del trabajo, etcétera; $d$ ) la crítica de las ideologías se capitaliza en crítica al marxismo y otras posturas humanistas y socialistas, y la crítica a las utopías se vuelca sobre las igualitarias o que busquen mecanismos redistributivos; e) la crítica de la integración modernizadora transforma la heterogeneidad estructural en una muestra de la diversidad (Hopenhaim, 1990:11-14). ${ }^{19}$

Junto a esto es muy importante recordar lo que destaca Sánchez Vazquez: "El posmodernismo desplaza la atención de la acción a la contemplación de lo político y a lo estético" (Sánchez Vázquez, 1991:42); y lo que escribe Zemelman: "Este tipo

19. El texto luego analiza con más detalle las relaciones y diferencias, lo que por razones de espacio es imposible transcribir aquí. 
de análisis expresa una carencia de utopias que traduce un cierto derrotismo político, escepticismo cultural o conformidad psicológica" (Zemelman, 2000:35), así como que "en muchos países se aprecia la existencia de una intelectualidad cansada, derrotista, que incluso llega a perder la noción del futuro, pero que a la vez es capaz de impulsar refinados trabajos exegéticos a partir de análisis descontextualizados, prolongación de una nueva forma de eurocentrismo, con el consiguiente abandono de la urgente tarea de dar cuenta de realidades emergentes que no se ha llegado a comprender de manera cabal... Esta perspectiva se traduce en una falta de perspectiva que lleva al inmovilismo"' (Zemelman, 1996:25-26).

Quienes conozcan el mundo cultural general de las ciencias sociales y de la cultura de nuestro tiempo ¿no reconocen cómo todo lo citado se proyecta en su discurso dominante?, ¿no ven cómo instituciones y universidades que otrora fueran conocidas como difusoras de posturas donde su discurso tenía importantes connotaciones sociales a veces hasta casi "apocalípticos", ahora lo abandonan en la realidad (tal vez no en las palabras) para convertirse al código "de moda", eliminando de hecho en artículos y publicaciones todo contenido vinculado a "problemáticas anteriores" (las que, por supuesto, no han perdido su vigencia)?, ¿no observan también cómo sus difusores prácticamente nunca salen del "discurso" para intervenir aunque sea mínimamente en acciones del mundo social o político, ni siquiera en simples firmas de apoyo a importantes demandas de la llamada sociedad civil, lo que no puede dejar de producir impacto en los alumnos receptores de tales posturas por lo que le muestran qué es importante y qué no y por "su carácter desmovilizador y despolitizador'? (Jimenez Cabrera, 1992:56).

\section{Dos revistas y un ejemplo comparativo}

Con base en todo lo anterior pueden plantearse dos grandes campos dentro del que era el paradigma crítico central de épocas pasadas: aunque se plantee una postura dicotómica extrema, está la de quienes mantienen tales posturas pero discutiéndolas y buscando renovarlas de acuerdo a tal cuestionamiento, y el de sectores que buscan perspectivas nuevas que básicamente entienden de manera distinta el campo de lo político e incluso el de la comunicación. Como ejemplo de tales posturas pueden verse dos publicaciones del ámbito universitario que las representan: Comunicación y Sociedad, del Departamento de Estudios de la Comunicación Social de la Universidad de Guadalajara, y Versión. Estudios de Comunicación y Politica, de la carrera de comunicación de la Universidad Autónoma Metropolitana-Xochimilco. 
En Comunicación y Sociedad puede observarse un manifiesto mantenimiento de la postura crítica conocida desde hace mucho tiempo, aunque se reitera que no de manera estática y con los vicios reconocidos que tuvo por mucho tiempo. Al contrario, no faltan los reconocimientos de éstos y las aperturas a campos antes no prohibidos pero de alguna manera sí estigmatizados. Todo ello quiere decir que se mantiene y renueva el estudio de "viejas" problemáticas que por supuesto no sólo no han perdido importancia sino, por el contrario, mantienen e incrementan su peso: el control de los medios de difusión a nivel nacional e internacional en estos períodos de globalización, el estudio de los contenidos de los mensajes que se transmiten, las nuevas características y formas de utilización de los medios para el mantenimiento del control social, el análisis y crítica —en el sentido real de este último términode los marcos teóricos hoy vigentes en el estudio de la comunicación, etcétera. Pero también se incorporan aspectos como el de los estudios de la recepción, los medios como parte del mundo de la cultura, la significación de las nuevas tecnologías, etcétera.

Pero un aspecto sobresaliente y especialmente destacable de esta postura es $s u$ constante aterrizaje en la realidad concreta de nuestro mundo y época concreta. Esto quiere decir que no flota en especulaciones abstractas sino que estudia y analiza formas específicas: desde la estructura de los medios en distintos países o regiones nacionales (caso de la prensa de Guadalajara, su sede) hasta el papel de los medios en el modelo neoliberal vigente. Un tema especialmente relevante que ha abordado de manera constante es el rol de los medios, a nivel local y nacional, en los últimos procesos electorales, temática de incuestionable valor al ser un aspecto relevante de su papel en los presentes tiempos.

En este caso, como representativo de una postura, se observa el interés en el conocimiento de una realidad específica y las causas que determinan una situación y un discurso de los medios. Con los límites que tiene una investigación sobre las comunicaciones masivas para un cambio en la estructura social, se ofrecen materiales para al menos un conocimiento de este cada vez más importante aspecto de nuestro mundo y su importancia en la dinámica social. Esto con independencia del vínculo que en ese caso se produce entre comunicadores y comunicólogos (en algunos casos vinculados a trabajos concretos en importantes medios de Jalisco).

Con todo esto se quiere decir que la lectura de Comunicación y Sociedad permite un acercamiento a la comprensión de un mundo concreto que reconocemos como nuestro, o sea con sus problemas y realidades a partir de enfoques que rechazan ciertos "dogmas" de un marco teórico al que no renuncian en bloque por imperativo de las "modas" actuales. 
El otro ejemplo no es la inversa pero muy cercano a ella. Se inscribe en la vieja idea de que hay que buscar lo nuevo, aunque siempre señalando el aparente mantenimiento de una postura crítica frente a la cultura y los medios. En este sentido una revisión del contenido de los nueve números hasta ahora aparecidos de Versión es muy clara respecto a sus intereses y desintereses, así como sobre sus marcos teóricos explícitos e implícitos. Lo primero que se observa es una clara adhesión a nuevas formas o campos de estudio de la comunicación, antes inexistentes. El más importante de ellos es sin duda el que surge a partir de romperse, con la relativa especificidad comunicativa para incluirla dentro del ámbito de la cultura, el sentido antes apuntado y con todos sus vicios. Los otros dos campos prioritarios de esa revista y del marco teórico que la produce son el análisis del discurso y el descubrimiento del incuestionablemente muy valioso análisis del proceso de recepción. Todos aspectos no sólo útiles sino incluso fundamentales para el proceso comunicativo global.

El problema de tal versión teórica es que nunca aterriza en nuestra realidad concreta y parece estar al margen de una historia concreta que se encuentra a un costado. En efecto, la lectura de esa revista puede hacerse casi en cualquier lugar del mundo - exagerando, aunque gráficamente, en México, en Afganistan, en Chechenia, etcétera - y se lee igual en tanto parece no tener territorialidad. Los "viejos" temas de la postura crítica de otros tiempos simplemente han desaparecido, aunque ya se vio que tales problemas no sólo se mantienen sino que se han incrementado. Mucho sobre cultura en general, pero poco sobre formas concretas de ésta, y poco vinculadas a los medios. Gran importancia al discurso, a la semiótica y a los procesos de recepción, pero también con una generalidad desterritorializada y ahistórica. Incluso, a pesar de que lleva el título de Estudios de comunicación y politica, esta última tiene las características antes citadas y de la revista: una absoluta generalidad que nunca aterriza en nada concreto. De esta manera parece que la concretización histórica molesta y resulta mejor hablar de ella pero sin especificarla, con lo cual se la abstractifica y de tal manera no ocasiona problemas. En definitiva es lo mismo que dentro del psicoanálisis hacen las corrientes estructuralistas del marco lacaniano o "lacanista": reconocen a la cultura como un aspecto fundamental en la constitución del Sujeto, pero la ven como estructura, es decir siempre presente pero sin analizarla en sus formas concretas de cada lugar y época histórica, lo que en definitiva no molesta mucho a nadie. Son en definitiva las ventajas de los no aterrizajes, que hasta permiten tener una imagen cuestionadora y critica pero sin sus riesgos y compromisos. 


\section{Final reiterativo y poco optimista}

Reiterativo porque sólo reiterará muy brevemente en lo ya planteado: el cada vez mayor y más rápido desarrollo de los sistemas de difusión masiva incrementa su peso en todos los vínculos y relaciones sociales, políticas y económicas, su importancia en la formación y consolidación del "imaginario social" y del control social, su aporte a la construcción del sujeto psicosocial (Guinsberg, 1985). Y, consecuentemente, en la cada vez mayor necesidad de verlos como partes integrantes sustantivas de tales realidades sociales, políticas y económicas. En tal perspectiva, y ante los cambios que de manera vertiginosa se producen en los mismos, es incuestionable la urgencia y pertinencia de estudiarlos e investigarlos en sus características e impactos, pero nunca prescindiendo del contexto social, politico y económico en que se ubican y les dan sentido, ni tampoco olvidando una visión crítica cada vez más imprescindible que exige retomar temáticas ya desarrolladas (sistemas de propiedad de los medios, contenidos de las emisiones, formas actuales de las industrias culturales, etcétera), sin que esto signifique olvidar una permanente revaluación y autocritica de lo realizado.

Y poco optimista también por lo ya planteado que surge de ver lo creciente en nuestro campo: así como perspectivas anteriores fueron producto del "espíritu" de las épocas en que se gestaron y desarrollaron, las actuales también lo son, por lo que es válido pensar - sin caer en posturas mecanicistas o de vulgar "reflejo"- que de no producirse cambios en las actuales condiciones las posiciones críticas se mantendrán en sectores reducidos mientras se incrementan las "integradas" en diferentes niveles.

Aunque, claro está, sería muy valioso que los hechos muestren que lo anterior es una equivocación.

\section{Bibliografía}

Almeyra, Guillermo (2000), “Los intelectuales en el huracán”, en La Jornada, México, 5 de marzo.

Barenblit, Valentín (1997), "Prólogo" a Galende, Emiliano, Por un horizonte incierto. Psicoanálisis y Salud mental en la sociedad actual, Paidós, Buenos Aires. 
Becker, Jörg (1994), “El pensamiento posmoderno”, revista Telos, Fundesco, Madrid, n. 38.

Bonilla Vélez, Jorge (1995), Violencia, medios y comunicación, Trillas/FELAFACS, México.

Brünner, José J. (1998), Globalización cultural y posmodernidad, Fondo de Cultura Económica, Santiago de Chile.

Cerroni, Umberto (1973), Técnica y libertad, Fontanella, Barcelona.

De Moragas i Spá, Miquel (1997), "Debemos transformar el conocimiento en bienestar social”, reportaje de Ricardo Haye, en Chasqui, CIESPAL, Quito, 59.

Esteinou, Javier (1997), "Investigación de la comunicación, leyes de mercado y final de siglo", revista Comunicación y Sociedad, Universidad de Guadalajara, n. 30. Follari, Roberto (1993), Posmodernidad, filosofia y crisis politica, Rei Argentina/Instituto de Estudios y Acción Social/Aique Grupo Editor, Buenos Aires.

(1999), Comunicología latinoamericana: disciplina a la búsqueda de objeto, inédito.

Guinsberg, Enrique (1985), Control de los medios, control del hombre. Medios masivos y formación psicosocial, $1^{\mathrm{a}}$ ed. Nuevomar, $2^{\mathrm{a}}$ ed. Pangea/UAM-X, México, 1989.

- (1990a), "Necesidad y riesgos del estudio del momento de la recepción", revista Telos, FundESCO, Madrid, n. 24.

— (1990b), “En la búsqueda de nuevos paradigmas para el estudio de la comunicación?", revista Comunicación y Sociedad, Universidad de Guadalajara, No $10-11$.

- (1991a), "La relación hombre-cultura: eje del psicoanálisis", revista Subjetividad y Cultura, México, n. 1, y en Normalidad, conflicto psíquico, control social, Plaza y Valdés/UAM-Xochimilco, $2^{\text {a }}$ ed. 1996.

- (1991b), "Recuperar el estudio del receptor. Dialéctica subjetivo-social en los medios masivos", revista Telos, Fundesco, Madrid, n. 25.

— (1994), "El psicoanálisis y el malestar en la cultura neoliberal", revista Subjetividad y Cultura, México, n. 4, y en Normalidad, conflicto psíquico, control social, Plaza y Valdés/UAM-Xochimilco, $2^{\mathrm{a}}$ ed. 1996.

- (1996a), "¿Qué buscan los receptores? Una perspectiva psicológica y psicoanalítica", revista Telos, Fundesco, Madrid, n. 48.

- (1996b), "Las 'religiones laicas' de nuestro tiempo", revista Subjetividad y Cultura, México, n. 6.

(1996c), "La salud mental en nuestros tiempos de cólera", en El sujeto de la salud mental a fin de siglo, UAM-Xochimilco. 
(1997a), "Desde la lectura de El malestar en la cultura: los psicoanálisis ¿entre la peste y la domesticación?", revista Imagen Psicoanalitica, AMPP, México, n. 9.

(1997b), "La 'fábrica de sueños' en nuestros tiempos posmodernos y neoliberales", revista Subjetividad y Cultura, México, n. 9.

(1998), "Placer y deseo en los procesos de recepción. Una aproximación psicoanalítica", revista Comunicación y Sociedad, U. de Guadalajara, 33.

- (1999), "Proyectos, subjetividades e imaginarios de los 60 a los 90 en Latinoamerica", revista Argumentos, DCSH/UAM-X, México, n. 32-33.

- (2000a), "Lo light, lo domesticado y lo bizantino en nuestro mundo $p s i$ ", revista Subjetividad y Cultura, México, n. 14.

- (2000b), "La inseguridad de y en nuestra cultura", en Anuario de Investigación 1998, Departamento Educación y Comunicación UAM-Xochimilco. Hodge, Bob, y Tripp, David (1986), Los niños y la televisión, Planeta, Barcelona. Hopenhaim, Martín (1990), "El debate postmoderno y la dimensión cultural del desarrollo", revista Relaciones, Montevideo, n.76.

Jimenez Cabrera, Edgar (1992), "El modelo neoliberal en América Latina", revista Sociológica, UAM-Azcapotzalco, México, n. 19.

Kaplun, Mario (1988), "Los Mattelart hoy: entre la continuidad y la ruptura. Una visión desmitificadora de los 'nuevos paradigmas"', revista Dia-logos de la Comunicación, FELAFACS, Lima, n.21.

Kundera, Milan (1990), La inmortalidad, Tusquets Editores, México.

Marques de Melo, José (1991), "En crisis la investigación académica de la comunicación en AL: Marques de Melo", reportaje de Omar R. Martínez, Revista Mexicana de Comunicación, México, n. 18.

Mattelart, Armand (1994), "Nuevos horizontes de la comunicación. El retorno de la cultura", revista Telos, Fundesco, Madrid, n. 37.

- (1998), La mundialización de la comunicación, Paidós, Barcelona.

Maza, Enrique (2000), "Las megafusiones de la comunicación: el mundo bajo control", revista Proceso, México, n. 1227, 7 de mayo 2000.

Marcuse, Herbert (1985), El hombre unidimensional, Planeta-De Agostini, México. Orozco Gómez, Guillermo (1997), La investigación de la comunicación dentro y fuera de América, Latina. Tendencias, perspectivas y desafios del estudio de los medios, Ediciones de Periodismo y Comunicación, Universidad Nacional de La Plata, La Plata.

Montoya Vélez, Martha Elena (1993), "Conversaciones con Jesús Martín-Barbero", revista Intermedios, Dirección de Radio, Televisión y Cinematografia de la Secretaría de Gobernación, México, n. 7. 
Reguillo, Rossana (1997), "Más allá de los medios. Diez años después”, revista Comunicación y Sociedad, Universidad de Guadalajara, n. 30.

Renero Quintanar, Martha (1998), "Una mirada al campo de la comunicación. Conversación con Jesús Martín-Barbero", entrevista de revista Comunicación y Sociedad, Universidad de Guadalajara, n. 34.

Pasquali, Antonio (1993), "La investigación en Latinoamérica no está muerta: Pasquali”, reportaje de Omar.R.Martínez, Revista Mexicana de Comunicación, México, n. 27.

Saintout, Florencia (1998), "De los medios a las mediaciones: diez años después", Revista Mexicana de Comunicación, México, n. 52.

Sánchez Ruiz, Enrique (1997), “Algunos retos para la investigación mexicana de comunicación. Una reflexión personal (en diálogo con Raúl Fuentes)", revista Comunicación y Sociedad, Universidad de Guadalajara, n. 30.

Sánchez Vázquez, Adolfo (1991), "Posmodernidad, posmodernismo y socialismo", en El cielo por asalto, Buenos Aires, Año I n. 3.

Schiller, Herbert ( 1992), “A quién pertenece el poder de los medios? Una concepción cambiante", revista Comunicación y Sociedad, U. de Guadalajara, n. 14-15. Schmucler, Héctor (1993), "Reemplacemos denuncismo por espíritu crítico", reportaje de O.R.Martínez, Revista Mexicana de Comunicación, México, n. 27.

Sokal, Alan, y Brincman, Jean (1999), Imposturas intelectuales, Paidós, Barcelona. Thompson, John (1993), Ideología y cultura moderna, UAM-Xochimilco, México, 1993. Vasallo de Lopez, María Immacolata (1995), "Recepción de medios, clases, poder y estructura. Cuestiones teórico-metodológicas de investigación cualitativa de la audiencia de los medios de comunicación de masas", revista Comunicación y Sociedad, Universidad de Guadalajara, n. 24.

Zemelman, Hugo (1996), Problemas antropológicos y utópicos del conocimiento, El Colegio de México, México.

(2000), “Chile 1990-99, ¿Un proceso democrático inmóvil?, revista Memoria, México, n. 132 